Review

\title{
Narrative Review of Surgery for Myasthenia Gravis
}

\author{
Aaron R. Dezube MD*, Ashley L. Deeb MD, Michael T. Jaklitsch MD
}

Division of Thoracic and Cardiac Surgery, Brigham and Women's Hospital, Harvard Medical School. 75 Francis St. Boston, MA 02115, USA; E-Mails: Adezube@partners.org; Adeeb@partners.org; Mjaklitsch@bwh.harvard.edu

* Correspondence: Aaron R. Dezube; E-Mail: Adezube@partners.org

Academic Editors: Patrizia Longone and Ian Johnson

Special Issue: Myasthenia Gravis

OBM Neurobiology

2021, volume 5, issue 4

doi:10.21926/obm.neurobiol.2104109
Received: June 25, 2021

Accepted: October 03, 2021

Published: October 15, 2021

\begin{abstract}
Myasthenia Gravis (MG) is a rare autoimmune disorder characterized by antibody mediated blockade of neuromuscular transmission. Up until the last decade, evidence suggesting benefit of thymectomy for myasthenia gravis has been based on non-randomized control studies. Our paper serves as an expert narrative review of new literature pertaining to surgical management of myasthenia gravis based on review of articles from PubMed and Cochrane database from date of inception through June 14, 2021. We used the MeSH search terms: "myasthenia gravis"; "thymectomy"; "thymoma"; and "surgery" to identify any new relevant articles for inclusion in our review. The results of these studies are summarized below. We reviewed multiple articles including two randomized control trials. As a result of these studies over the past decade, the American Academy of Neurology's most recent practice advisory, published online March 25, 2020, gives a level 'B' recommendation for thymectomy for MG in patients with acetylcholine receptor antibody-positive generalized MG age 18-65 years old. They additionally noted the need for further discussion surrounding the benefits and risks of surgery and whether minimally invasive approaches to thymectomy would provide the same benefits as the traditional transsternal approach. Evidence recommending thymectomy during pregnancy remains limited due to lack of available data. Emerging evidence suggests
\end{abstract}

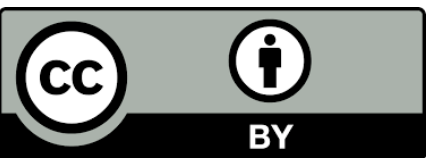

(C) 2021 by the author. This is an open access article distributed under the conditions of the Creative Commons by Attribution License, which permits unrestricted use, distribution, and reproduction in any medium or format, provided the original work is correctly cited. 
that performance of video-assisted or robotic-assisted thymectomy is feasible, but further study is needed due to a lack of randomized control trials.

\section{Keywords}

Myasthenia gravis; thymectomy; antibody; surgery; minimally invasive; robotic

\section{Introduction}

Myasthenia gravis (MG) is a rare autoimmune disorder characterized by antibody mediated blockade of the neuromuscular transmission causing skeletal muscle weakness $[1,2]$. The reported prevalence of MG ranges from 7.7 to 20 cases per 100,000 population and it affects twice as many females as males $[3,4]$. MG has two forms: ocular where the eyelids and extraocular muscles are affected, and generalized where variable types of muscles are affected. It is further separated into subtypes by age, antibody involvement (anti-acetylcholine receptor (AChR) positive, anti-muscarinic (MuSK) positive, anti-lipoprotein receptor-related protein-4 (LRP4) positive, and seronegative) and presence of thymoma $[5,6]$.

The association between MG and thymic tumors was first described by Weigert in 1901 [7]. Thymomas are considered rare tumors accounting for only $1 \%$ of malignancies but $50 \%$ of anterior mediastinal masses [8]. It is now understood that $10-30 \%$ of patients with MG have thymomas [911]. Of note, a recent systematic review placed that number closer to a pooled estimate of $21 \%$ ( $95 \%$ Confidence Interval (Cl): 20-22\%) across population-, hospital- and surgery-based studies with considerable variation by region (13\%; $95 \% \mathrm{Cl} 12-15 \%$ for Americas to $29 \%$; $95 \% \mathrm{Cl} 26-31 \%$ for Asian cases) [12].

Initial reports of symptomatic MG improvement following thymectomy for thymoma and nonthymomatous disease were limited to case reports and large case series in the early $20^{\text {th }}$ century starting with Blalock et al. in 1944 [13-15]. There were no well-designed prospective randomized trials examining surgical thymectomy until the 2016 New England Journal of Medicine MGTX study [16]. This led to disagreement about the role of thymectomy for MG due to lack of understanding of the underlying physiologic basis for remission, lack of randomized trials, and reports of spontaneous remission without surgery ranging from 10-20\% [10].

Furthermore, indications for thymectomy are not uniform. An understanding of MG subtypes is important for surgical decision making, often in conjunction with a MG specialist. Current indications include non-pregnant adults aged 18-65 with MG and thymomas regardless of subtype and non-thymomatous MG (anti-AChR antibody positive) with generalized symptoms [17]. While thymectomy for double-seronegative MG (anti-AChR antibody negative and anti-MuSk antibodynegative) has been proposed [18], thymectomy is not typically recommended for patients with antiMuSK antibodies due to differences in thymic pathology and lack of randomized trials) [19]. It is uncertain if thymectomy in patients with anti-LRP4 positive MG is beneficial due to lack of larger, randomized trials. Some small case studies, however, have demonstrated an improvement in symptoms after thymectomy in anti-LRP4 positive MG cases [20, 21]. 
Our paper serves as an expert narrative review of new literature over the last decade pertaining to the surgical management of myasthenia gravis including landmark trials, indications for surgery, advances in operative techniques, and post-operative outcomes associated with thymectomy.

\section{Materials and Methods}

Articles for inclusion were identified by two authors after search of PubMed, Medline and Cochrane library. Articles included were performed from date of inception through June 12th, 2021. Final incorporation into the review was decided by an independent senior author. We used the MeSH search terms: "myasthenia gravis"; "thymectomy"; "thymoma"; and "surgery" to identify any new relevant articles for our review. We excluded articles not written in English. The results of these studies are summarized below.

We also checked references of relevant articles and review articles for inclusion. In addition, after consensus review between all authors, articles deemed relevant and not identified in above mentioned searches were added to the review.

\section{Results}

\subsection{Major Studies Investigating Thymectomy for Myasthenia Gravis}

In the last decade prior to the NEJM MGTX RCT [16], no randomized trials existed involving surgical treatment of MG. A systematic review in 2013 by Cea et al. [22] identified most studies as case series or retrospective cohorts with no properly designed analytical observational studies investigating the role of surgery for MG. The three retrospective cohort studies identified were ultimately excluded due to methodological flaws [23-25]. Reporting was heterogenous with nonconventional outcomes in the report by Bedlack et al. [26] and there was insufficient patient data in the Kawaguchi et al report [25]. In the case of Buckingham et al. [24], despite an increased proportion of remission in MG patients undergoing thymectomy, the matched medical arm was considered too limited as compared to the surgical patients ( $n=24$ out of 104 patients).

In August 2016, the NEJM published the first prospective multicenter randomized controlled trial (MGTX) comparing extended transsternal thymectomy and alternate day prednisone versus alternate day prednisone alone [16]. A total of 126 patients ranging in age from 18 to 65 years were randomized over 6 years at 36 sites from 2006-2012. Patients were included if they had generalized non-thymomatous myasthenia gravis of 5 years or less duration with Myasthenia Gravis Foundation of America (MGFA) clinical class II to IV [27]. The primary end point was quantitative time-weighted MG score (range 0-39) over a 3-year period. The thymectomy arm was statistically superior for both improved symptoms (as evidenced by a time-weighted average Quantitative Myasthenia score; 6.15 vs. 8.99, $p<0.001)$, less hospitalizations for exacerbations ( $9 \%$ vs. $37 \%, p<0.001)$ and lower dose requirement of both prednisone and azathioprine $(17 \%$ vs. $48 \%, p<0.001)$. A main point was that treatment related complications were similar, with lower rates of immunosuppressive side effects $(p<0.001)$ or distress related symptoms $(p=0.003)$ in the thymectomy cohort. However, this study failed to achieve their target goal of 200 patients and had to increase the age of their cohort and the duration of disease to increase accrual, while limiting their cohort to those with only mild to moderate disease, ocular MG or seronegative MG [28]. Furthermore, only limited studies in the elderly population have followed this study [29]. 
To date, the most recent systematic review and meta-analysis by Cataneo et al. [4] included 19 articles encompassing 5,841 patients (2,911 surgical, 2,930 non-surgical) and two RCTs (notably the MGTX study considered to be low risk of bias and a small Columbian study by Lorenzana et al. considered to be moderate risk of bias) $[16,30]$ with the remainder being case series or case-control studies. Cataneo et al. [4] found thymectomy, compared to medical therapy, led to increased remission (pooled odds ratio (OR) 2.34, 95\% Cl 1.79-3.05: $\mathrm{I}^{2}=56 \%$ ). When limited to 4 studies with matched cohorts, this number increased (OR 4.10,95\% Cl 2.25-7.44; $1^{2}=20 \%$ ). Unfortunately, due to heterogeneity (87\%) pooled analysis of improvement was unable to be performed.

As a result of these studies over the past decade, the American Academy of Neurology's (ANN) most recent practice advisory published online March 25, 2020 [17] gives a level 'B' recommendation for thymectomy in patients with anti-AChR positive generalized MG age 18-65 years old. Their recommendation also notes the need for discussion surrounding the magnitude of the benefits and risks of surgery. There is also uncertainty whether the benefit obtained by transsternal thymectomy will also be obtained by minimally invasive approaches. Societal guidelines do not recommend thymectomy during pregnancy due to lack of available data at this time [31]. Details of technique and outcomes for surgical approach including open and MIS techniques will be described below in more detail.

\subsection{Perioperative Management and Workup}

\subsubsection{Preoperative Care}

In addition to typical elements of a preoperative assessment, certain things should be considered when evaluating a patient with myasthenia gravis. A patient's disease should be well controlled and stable before undergoing surgery [32-35]. Various studies have investigated potential predictors of postoperative myasthenic crisis. Leventhal et al. examined several patient factors in 24 patients with myasthenia gravis who underwent thymectomy via multivariate analysis and found that duration of disease greater than 6 years, presence of respiratory disease such as chronic obstructive pulmonary disease, pyridostigmine dosage greater than $750 \mathrm{mg} /$ day, and vital capacity $<2.9$ L were significantly correlated with need for postoperative ventilation [36]. Other studies have found presence of bulbar symptoms, Osserman stage, previous myasthenic crisis, intraoperative blood loss $>1000 \mathrm{~mL}$, and anti-acetylcholine receptor antibodies $>100 \mathrm{nmol} / \mathrm{mL}$ as risk factors of postoperative myasthenic crisis [37-42]. Thus, when collecting a history, clinicians should pay particular attention to the presence of any bulbar symptoms, history of myasthenic crisis, dyspnea, infection, current medications for myasthenia gravis, as well as other diseases as these may lead to negative outcomes. Other autoimmune disorders as well as endocrine disorders are often seen with myasthenia gravis and the presence of some, such as thyroid disorders, may affect symptoms [28, 31, 39, 40].

In addition to a thorough history and physical, certain preoperative tests may be helpful in assessing a patient with myasthenia gravis. As discussed above, some studies have found that pulmonary function tests may indicate which patients are at higher risk of developing myasthenic crisis or respiratory problems postoperatively. One study examined 393 patients at multiple medical centers in Japan who underwent thymectomy and found that a vital capacity $<80 \%$ was a risk factor for postoperative myasthenic crisis [43]. Additionally, a recent meta-analysis identified preoperative lung function as an independent risk factor for myasthenic crisis after thymectomy (MCAT) (OR = 5.71, 95\% Cl 3.11-10.48, $\mathrm{p}<0.00001$ ) [42]. Routine preoperative EKG on patients with MG is 
additionally useful as some patients may have conduction disorders and arrhythmias. Any evidence of congestive heart failure in the preoperative workup should be further investigated with echocardiography [32, 35]. Additionally, myasthenia gravis antibodies, tumor markers, and thyroid functions tests may be useful labs in the workup of a patient for thymectomy.

Obtaining the previously mentioned tests not only informs surgeons and anesthesiologists of the level of care a patient will need postoperatively, but also identifies modifiable factors that can be addressed or optimized before surgery. The care of patients with MG should be performed in collaboration with multiple subspecialties. Neurologists work closely with the perioperative team and optimize the patient's immunotherapy regimen and medication doses [31]. For patients with severe or unstable disease, preoperative intravenous immunoglobulins (IVIG) or plasmapheresis may be helpful [31, 34, 44, 45]. Additionally, any concurrent autoimmune or endocrine disorders should be appropriately treated under the guidance of rheumatologists, endocrinologists, and the patient's primary care physician preoperatively. Conduction disorders or other cardiac dysfunctions detected on preoperative EKG should trigger involvement of cardiology for appropriate workup and treatment.

Imaging is also a vital tool in the preoperative evaluation of a patient for thymectomy. Crosssectional imaging, specifically computed tomography (CT) with contrast, can inform the surgeon on the size of the lesion and whether it invades adjacent structures which determines the degree and method of resection. Specifically, if an enlarged lobe favors one side of the patient, it affects the operative approach in minimally invasive cases. Additionally, subtle relationships of the cervical horns of the thymus to the innominate vein can be helpful during dissection, thus it is useful to visualize this on preoperative imaging. Finally, these scans can identify any enlarged lymph nodes. Positron emission tomography (PET) scans can provide additional information about the metabolic activity of the lesion and magnetic resonance imaging (MRI) may also be a useful imaging study.

\subsubsection{Intraoperative Care}

There are various medications utilized intraoperatively that can either exacerbate MG symptoms or cause CNS depression and respiratory distress [46]. Thus, careful consideration should be taken in the intraoperative management of patients with MG.

Premedication with opioids or sedatives should be performed cautiously due to the potential for respiratory depression and upper airway obstruction in certain patients [46, 47]. When considering agents to induce and maintain general anesthesia, it is important to note that some may worsen symptoms. For example, studies have found a reduction in neuromuscular transmission with inhaled anesthetics in MG patients [48]. However, there have been cases of safe use of these anesthetics as well as total intravenous anesthesia with propofol or remifentanil in patients with MG $[49,50]$.

Neuromuscular blocking agents (NMBAs) should be avoided given that these agents can cause myasthenic crisis and other unpredictable reactions in these patients. If a NMBA must be utilized intraoperatively, it is recommended to use a nondepolarizing NMBA at a dose reduced by one half to two thirds $[35,46,51]$. Sugammadex, a substance that deactivates nondepolarizing NMBAs by enveloping them, is the recommended choice for reversal given that it is not affected by anticholinesterase medication. Neostigmine, on the other hand, can be unpredictable in its reversal effects and could lead to myasthenic or cholinergic crisis. Many studies have supported the use of 
Sugammadex including a retrospective review of a national inpatient database which found that patients reversed with Sugammadex had decreased instances of postoperative myasthenic crisis, decreased hospital costs, and decreased hospital length of stay [52].

\subsubsection{Postoperative Care and Complications}

Most patients after thymectomy are extubated in the operating room. While not always indicated, a low threshold for intensive care admission may be necessary. Need for sternal precautions post operatively is based on surgical approach. Most patients will receive a chest tube and daily chest $x$ rays (CXRs) will be obtained, with removal of chest tubes when appropriate. While overall operative mortality is $<1 \%$ [53], routine complications are possible including pneumonia, infection, or fluid changes, and close attention must be turned to a patient's respiratory status. Additionally, consultation with the neurology team is often crucial in the care of these patients. Monitoring for ocular symptoms or traditional methods of respiratory monitoring in myasthenia gravis patients may be utilized. The challenge in post-operative care unique to myasthenia patients is the fact that post-operative lung infection is an independent risk factor for myasthenic crisis after thymectomy (MCAT) [42].

While no randomized controlled trials exist which examine differences in surgical technique and approach, a recent meta-analysis found no difference in complications between limited and extended thymectomies [54]. Studies comparing minimally invasive methods to open techniques have shown reduction in hospital length of stay and overall adverse events. However, this has not always been demonstrated for pulmonary outcomes when compared to the transcervical approach $[55,56]$. Furthermore, while VATS has been associated with less blood loss, it has been associated with higher phrenic nerve injury [57]. Further differences in outcomes by surgical method are discussed below.

\subsection{Surgical Approach to Management}

Since the first thymectomy performed in 1912 by Sauerbruch [14], countless new techniques have been developed over the years. Each technique varies not only in primary approach (transsternal, transcervical, or minimally invasive) but by the extent of resection. Additionally, each technique has many variations from the traditionally described procedure. For all of these techniques, surgeons should aim to completely resect thymic tissue, avoid injury to the phrenic, vagus, and recurrent laryngeal nerves, and avoid disruption of the capsule and dissemination in cases of thymoma [58]. The debate over which technique is superior has continued for years and still remains unanswered given the wide variability between studies and the lack of controlled studies. Table 1 demonstrates outcomes by thymectomy approach. In general, the tissue removed, and clinical outcomes as well as remission rates are nearly the same. Therefore, the correct surgical approach may be the one the individual surgeon prefers and is adept in. 
Table 1 Outcomes by thymectomy approach.

\begin{tabular}{|c|c|c|c|c|c|c|c|c|}
\hline Author (Ref.) & $\begin{array}{l}\text { Year } \\
\text { Published }\end{array}$ & No. of Patients & Approach & Remission* & $\begin{array}{l}\text { Overall } \\
\text { Complications }\end{array}$ & $\begin{array}{l}\text { Myasthenic } \\
\text { Crisis }\end{array}$ & Hospital LOS & $\begin{array}{l}30 \text { Day } \\
\text { Mortality }\end{array}$ \\
\hline $\begin{array}{l}\text { Masaoka et al. } \\
\text { [59] }\end{array}$ & 1996 & $\begin{array}{l}375 \quad(286 \\
\text { nonthymomatous, } \\
89 \text { thymomatous) }\end{array}$ & TS & $\begin{array}{l}\text { Nonthymomatous: } \\
45.8 \% \text { at } 5 \mathrm{yr}, 55.7 \% \text { at } \\
10 \mathrm{yr}, 50.0 \% \text { at } 20 \mathrm{yr} \\
\text { Thymomatous: } \\
23 \% \text { at } 5 \mathrm{yr}, 30 \% \text { at } 10 \\
\mathrm{yr}, 37.5 \% \text { at } 20 \mathrm{yr}\end{array}$ & N/A & N/A & N/A & $\mathrm{N} / \mathrm{A}$ \\
\hline Mack et al. [60] & 1996 & 33 & VATS & $\begin{array}{l}18 \% \text { mean follow up } \\
23.39 \text { mo. }\end{array}$ & $1(3 \%)$ & N/A & 4.12 days & 0 \\
\hline $\begin{array}{l}\text { Calhoun et al. } \\
\text { [61] }\end{array}$ & 1999 & 100 & $\mathrm{TC}$ & N/A & $8(8 \%)$ & $1(1 \%)$ & 1.22 days & 0 \\
\hline $\begin{array}{l}\text { Mineo et al. } \\
{[62]}\end{array}$ & 2000 & 31 & VATS & $\begin{array}{l}13 \% \text { at } 12 \text { mo., } 36 \% \text { at } \\
48 \text { mo. }\end{array}$ & N/A & $1(3.2 \%)$ & 5.2 days & 0 \\
\hline $\begin{array}{l}\text { de Perrot et al. } \\
\text { [63] }\end{array}$ & 2003 & 120 & $\mathrm{TC}$ & $91 \%$ at $10 \mathrm{yrs}$ & $4(3.3 \%)$ & $2(2 \%)$ & $\begin{array}{l}2 \text { days } \\
\text { (before } \\
\text { 1994), } 1 \text { day } \\
\text { (after 1994) }\end{array}$ & 0 \\
\hline $\begin{array}{l}\text { Chang et al. } \\
\text { [64] }\end{array}$ & 2005 & 15 & VATS & 5 follow up 33 mo & $1(6.7 \%)$ & $\mathrm{N} / \mathrm{A}$ & 8.22 days & $\mathrm{N} / \mathrm{A}$ \\
\hline & & 16 & TS & 6 follow up 29.38 mo & $2(12.5 \%)$ & N/A & 11.76 days & N/A \\
\hline $\begin{array}{l}\text { Kattach et al. } \\
\text { [65] }\end{array}$ & 2006 & 85 & TS & $17 \%$ at $4.5 \mathrm{yrs}$ & $13(15 \%)$ & N/A & 8 days & 0 \\
\hline $\begin{array}{l}\text { Shrager et al. } \\
\text { [66] }\end{array}$ & 2006 & 164 & $\mathrm{TC}$ & $33 \%$ at $3 y r, 35 \%$ at $6 y r$ & $11(7.3 \%)$ & N/A & 1.10 days & 0 \\
\hline
\end{tabular}


OBM Neurobiology 2021; 5(4), doi:10.21926/obm.neurobiol.2104109

\begin{tabular}{|c|c|c|c|c|c|c|c|c|}
\hline \multirow[t]{2}{*}{ Lin et al. [67] } & 2009 & 38 & VATS & $\begin{array}{l}32 \% \text { mean follow up } \\
38.5 \text { mo }\end{array}$ & $2(5 \%)$ & N/A & 5.6 days & 0 \\
\hline & & 22 & TS & $\begin{array}{l}36 \% \text { mean follow up } \\
86.7 \text { mo }\end{array}$ & $1(5 \%)$ & $N / A$ & 8.1 days & 0 \\
\hline \multirow{2}{*}{$\begin{array}{l}\text { Rucket et al. } \\
{[68]}\end{array}$} & 2011 & 79 & VATS & $20.3 \%$ at $42 \mathrm{mo}$ & $2(2.5 \%)$ & $N / A$ & $\mathrm{~N} / \mathrm{A}$ & 0 \\
\hline & & 74 & Robot & $39.3 \%$ at $42 \mathrm{mo}$ & $2(2.7 \%)$ & $\mathrm{N} / \mathrm{A}$ & $\mathrm{N} / \mathrm{A}$ & 0 \\
\hline $\begin{array}{l}\text { Freeman et al. } \\
\text { [69] }\end{array}$ & 2011 & 75 & Robot & $\begin{array}{l}28 \% \text { mean follow up } 45 \\
\text { mo }\end{array}$ & $5(6.6 \%)$ & 0 & 2.2 days & 0 \\
\hline $\begin{array}{l}\text { Tomulescu et } \\
\text { al. [70] }\end{array}$ & 2011 & 240 & VATS & $\begin{array}{l}61 \% \text { median follow up } \\
67 \text { mo }\end{array}$ & $12(5 \%)$ & $1(0.4 \%)$ & 2.1 days & 0 \\
\hline $\begin{array}{l}\text { Marulli et al. } \\
{[71]}\end{array}$ & 2013 & 100 & Robot & $28.5 \%$ at 5 yrs & $6(6 \%)$ & $1(1 \%)$ & 3 days & 0 \\
\hline \multirow[t]{2}{*}{ Xie et al. [72] } & 2016 & 50 & TS & $42 \%$ at 5 yrs & $20(40 \%)$ & $11(22 \%)$ & 11 days & $\mathrm{N} / \mathrm{A}$ \\
\hline & & 31 & VATS & $52.1 \%$ at 5 yrs & $2(6.5 \%)$ & $1(3.2 \%)$ & 9 days & N/A \\
\hline \multirow[t]{3}{*}{$\begin{array}{l}\text { Imielski et al. } \\
{[73]}\end{array}$} & 2020 & 69 & TS & $\begin{array}{l}* 94.2 \% \text { at } 5 \mathrm{yr}, 89.8 \% \text { at } \\
10 \mathrm{yr}\end{array}$ & N/A & $1.4 \%$ & 4.3 days & $\mathrm{N} / \mathrm{A}$ \\
\hline & & 97 & VATS & $\begin{array}{l}* 94.8 \% \text { at } 5 \mathrm{yr}, 90.7 \% \text { at } \\
10 \mathrm{yr}\end{array}$ & N/A & $0.7 \%$ & 2.4 days & $\mathrm{N} / \mathrm{A}$ \\
\hline & & 54 & Robot & $\begin{array}{l}* 96.2 \% \text { at } 5 \mathrm{yr}, 96.2 \% \text { at } \\
10 \mathrm{yr}\end{array}$ & N/A & & 1.3 days & N/A \\
\hline \multirow[t]{2}{*}{ Luzzi et al. [74] } & 2021 & 57 & Robot & $N / A$ & $31 \%$ & $\mathrm{~N} / \mathrm{A}$ & 5.25 days & $\mathrm{N} / \mathrm{A}$ \\
\hline & & 57 & TS & $\mathrm{N} / \mathrm{A}$ & $33 \%$ & $\mathrm{~N} / \mathrm{A}$ & 12.31 days & $\mathrm{N} / \mathrm{A}$ \\
\hline \multicolumn{9}{|c|}{ *Complete stable remission } \\
\hline \multicolumn{9}{|c|}{ LOS = length of stay } \\
\hline \multicolumn{9}{|c|}{ TS = Transsternal } \\
\hline \multicolumn{9}{|c|}{$\mathrm{TC}=$ Transcervical } \\
\hline
\end{tabular}


Thymectomies can be generally grouped into: transcervical thymectomy (T1), thoracoscopic thymectomy (T2) (VATS and robotic), transsternal thymectomy (T3) (with either a partial or full sternotomy), and transcervical and transsternal thymectomy (T4) via the Myasthenia Gravis Foundation of America (MGFA) thymectomy classification [27]. Additionally, each of these categories have subtypes which vary in degree of resection. These subtypes can be broadly summarized as either basic or extended. Only the thymus is removed in a basic resection. The entire thymus and surrounding fat tissue are removed in an extended resection. Transsternal thymectomy can either be completed with a full or partial sternotomy. Additionally, it can be further subdivided into the "standard" (T3a) and the "extended" techniques (T3b). The transcervical thymectomy can be further divided into the "basic" (T1a) or "extended" (T1b) resections. An extended transcervical thymectomy utilizes a specialized sternal retractor to improve visualization and achieve a greater degree of resection. The combined transcervical and transsternal thymectomy (T4), as its name implies, utilizes a neck and sternal incision to resect all possible thymic tissue in the neck and mediastinum. Finally, the thoracoscopic thymectomy can be subdivided into "classic" video-assisted thoracic surgery (VATS) (T2a) and thoracoscopic extended thymectomy (VATET) (T2b). While a classic video-assisted thymectomy is performed unilaterally, the extended version uses bilateral incisions as well as a cervical incision [27]. Of note, Sonett and Jaretzki listed a modified MGFA classification to include variations such as extended with partial sternal split and extended with videoscopic technology for transcervical thymectomy, unilateral and bilateral robotic thymectomy, and added infra-sternal thymectomy (T5) as a category [75].

Even though the thymectomy performed by Sauerbruch [14] was completed via a transcervical approach, the transsternal approach was initially popular amongst surgeons for thymectomy in MG and was considered standard. The first thymectomy specifically for myasthenia gravis was performed by Alfred Blalock in 1939 via a transsternal approach with improvement in symptoms [13]. He later reported the results of thymectomy in 6 patients with MG and later 20 patients with mostly positive results [76, 77]. Various other surgeons followed suit and reported on their experiences with transsternal thymectomy. However, given the invasiveness of the transsternal approach, attention turned back to the original transcervical thymectomy. Kirschner and colleagues reported the course of 21 patients who underwent thymectomy via the transcervical approach (T1a) and noted that patients had less pain postoperatively and ambulated early. Additionally, at one year follow up, nine patients had almost complete remission or improvement in symptoms and three had no change in symptoms (eight couldn't be evaluated due to recent thymectomy) [78]. Others supported the transcervical approach as a less invasive and more accepted procedure by patients $[78,79]$. However, there was significant concern that inadequate visualization would lead to incomplete resection and recurrence. Masaoka et al. noted that there was often additional thymic tissue within the mediastinal fat and advocated for the extended transsternal thymectomy [80]. They additionally published 20-year results with this method and noted favorable remission rates in patients with and without thymoma [59]. Jaretski et al found multiple accessory lobes of the thymus throughout the mediastinum and advocated for a more aggressive and complete resection via a combined transcervical and transsternal thymectomy [81, 82]. Various studies have supported the transsternal and combined transcervical and transsternal approaches including the MGTX study which utilized an extended transsternal approach [16].

A major development to the transcervical approach was in 1988 where Cooper et al reported a modified transcervical thymectomy (T1b) utilizing a novel sternal retractor and followed the 
outcomes of 65 patients over 8 years. Comparing the outcomes of these patients with those who had undergone transsternal thymectomy, they concluded that this new technique could have similar results [83]. They later published a retrospective review of 100 patients who had undergone transcervical thymectomy and found a mean operative time of 104 minutes, mean length of stay of 1.22 days, no significant postoperative complications, and significant reduction of Osserman grade in follow up ( 3 preoperatively to 1 postoperatively, $p<0.001$ ). They concluded that the transcervical approach was comparable to the transsternal approach and carried with it fewer complications and decreased length of stay [61]. With the previous recurrence and reoperation rates and the success of the extended approach, the basic transcervical approach was largely abandoned. Various other retrospective reviews throughout the years have supported the transcervical approach (along with some variations) and demonstrated similar outcomes to more invasive approaches [63, 66, 84]. The new extended transcervical approach additionally yielded similar complete remission rates to those of the sternotomy approach. A retrospective chart review by Shrager et al. [85] utilizing life table analysis found a $43 \%$ complete remission rate at 5 years compared to a $50 \%$ complete remission rate at 5 years in median sternotomy cases reported by Jaretski et al. [82]. It is important to note, however, that for consideration of transcervical thymectomy, a patient must be able to extend their neck adequately. Additionally, morbid obesity, prior mediastinal surgery, and thymoma whether present or suspected are contraindications to the transcervical approach. Conversely, some have argued that resection of well contained small thymomas or lesions $(<4 \mathrm{~cm})$ could be adequately resected via the transcervical approach [86].

In the 1990s, video thoracoscopy was introduced as a method of thymectomy [87-89]. Variations on laterality as well as the overall procedure have emerged over time. Additionally, in the early 2000s, the use of the robotic platform for thymectomy was introduced [90-92]. These approaches, much like the transcervical approach, were appealing due to their minimally invasive nature. However, much like the other approaches to thymectomy, it has been debated whether videoassisted thoracoscopic (VATS or robotic) thymectomy provides adequate resection and remission. Initial studies as well as studies detailing laterality and remission rates will be described in further detail in subsequent sections.

\subsection{Video-Assisted Thoracoscopic Thymectomy}

As previously discussed, the open (transsternal) approach was considered the gold standard for thymectomy for years. While the maximal approaches provided excellent excision of all thymic tissue, they also came with higher morbidity and were a large physiologic strain on patients, especially those with MG. With the development of minimally invasive procedures such as the transcervical thymectomy, came significant concerns over whether these approaches could provide extended thymectomy. Indeed, these concerns appeared correct for the original "standard" transcervical thymectomy which was abandoned with time. In the 1990s, several single center retrospective studies reported on the use of videoscopic approaches for thymectomy the first by Sugarbaker $[63,66,84]$. Similar to its minimally invasive predecessor, there were several concerns with this new approach, namely whether it could offer as adequate resection as the open approaches. 


\subsubsection{Laterality}

VATS thymectomy can be performed either unilaterally or bilaterally. Additionally, if approached unilaterally, a VATS thymectomy can be performed on either the left or right side of the patient. Those who prefer left sided thymectomy favor it for the extensive excision of perithymic tissue [62]. However, the left sided approach carries the potential for injury of the innominate vein and SVC junction. Those who prefer the right sided approach like the additional space provided and improved view of the superior vena cava as a landmark [60, 72, 93]. The right sided approach, however, has the potential for injury to the left phrenic nerve at the level of the left sided innominate vein. Currently, there is little data on bilateral vs unilateral VATS thymectomy, however, it is generally accepted that similar results can be achieved with either approach [94, 95]. Similarly, single center retrospective reviews haven't found significant differences in outcomes between laterality of VATS thymectomy [70, 72]. Thus, the decision between unilateral or bilateral VATS as well as left vs right sided approach depends largely on lesion (if present) location and surgeon experience and preference.

\subsubsection{VATS vs Open Approaches}

Various single center retrospective reviews have demonstrated that some of the clear advantages of VATS over open thymectomy are shorter hospital stay [55, 93, 96-98]. fewer postoperative complications [99], and decreased intraoperative blood loss [64, 100, 101]. The former is a particularly appealing benefit to minimally invasive options considering the ongoing COVID epidemic and the need to minimize exposure in a healthcare setting. There have been mixed results regarding operative time for VATS and transsternal thymectomy. Some retrospective studies have demonstrated no significant differences in operative time [55, 67]. Conversely, other retrospective and prospective studies have found significantly longer operative times with VATS thymectomy (197 \pm 35 min VATS vs $113 \pm 43$ min transsternal, $p<0.001$ ) [102] (4.2 hours VATS vs 1.8 hours transsternal, $p<0.05$ ) [64]. Intuitively, a minimally invasive approach would cause less pain and splinting and, thus, improved respiratory functioning postoperatively. A small prospective trial compared postoperative pulmonary function (via vital capacity, forced vital capacity, forced expiratory volume per second, and peak expiratory flow) between transsternal and VATS thymectomy in 20 patients and found that VATS patients had less impairment of their respiratory function immediately postoperatively and returned to their baseline functioning faster than those who underwent transsternal thymectomy [103].

Additionally, various studies have compared VATS thymectomy with more invasive approaches and have found similar rates of symptom reduction and remission [52, 60, 99, 101]. One single center retrospective study examined complete stable remission (CSR) rates. CSR is defined by the MGFA as no MG signs or symptoms for 1 year without therapy [27]. In patients who underwent extended unilateral VATS thymectomy, CSR occurred in $61 \%$ of patients with a median time of 18 months to achieving CSR. The probability of achieving CSR was $60 \%$ at 5 years and $88 \%$ at 10 years [89]. A recent meta-analysis compared CSR rates amongst various thymectomy approaches and found no significant differences in CSR at 3 years ( $R R 0.96,95 \% \mathrm{Cl} 0.72-1.27, p=0.74$ ) and 9 years (RR 1.51, 95\% Cl 0.99-2.30, $\mathrm{p}=0.05$ ) between extended transsternal and extended VATS [104]. With regards to symptom relief, a retrospective cohort study compared VATS to transsternal thymectomy in MG patients and found similar rates of medication cessation after surgery between the two 
groups (77.8\% VATS vs $65.4 \%$ transsternal stopped prednisone, $p=0.38 ; 65.2 \%$ VATS vs $42.5 \%$ transsternal stopped pyridostigmine, $p=0.08 ; 100 \%$ VATS vs $54.6 \%$ transsternal stopped immunosuppressives, $\mathrm{p}=0.46$ ) [55].

\subsection{Robotic Thymectomy}

In 2001, Yoshino et al reported on the first use of the da Vinci ${ }^{\circledR}$ Surgical System (Intuitive Surgical Inc., Sunnyvale, CA) in thoracic surgery for excision of a thymoma [90]. Others began publishing case studies of their experiences with robotic thymectomy including the first thymectomies performed for patients with MG in 2003 [91, 92]. As mentioned previously, minimally invasive approaches to thymectomy had gained favor due to less postoperative complications, shorter hospital length of stay, and improved cosmesis [55, 66, 99, 103]. Robotic-assisted thymectomy, specifically, was seen as an approach that could yield better visualization given the 3D high-definition camera as well as potentially improved dissection within the mediastinum given the 360 degrees of motion and articulating wrists [105].

\subsubsection{Laterality}

Much like the previous approaches, there are many variations to robotic thymectomy. Robotic thymectomy can be performed from either the left or right side of the patient. Those who prefer left sided thymectomy favor it due to its easier access to the mediastinal tissue and thymus as well as good visualization of both phrenic nerves. Conversely, the right sided approach provides more space but sacrifices adequate view of the left phrenic nerve. Regardless of the approach, the surgeon should not hesitate to add ports to the contralateral side if they encounter difficulty or convert to open. Additionally, the goal of robotic thymectomy, regardless of laterality or variation, is complete resection of all thymic tissue.

\subsubsection{Robotic vs Open Thymectomy}

Various studies have compared robotic thymectomy to open approaches. The advantages of the robotic system become very apparent when comparing robotic thymectomy to transsternal thymectomy. A meta-analysis of 18 studies examined various perioperative variables between robot and open groups and found no difference in operative times, mortality rates, or intraoperative complications but significantly lower blood loss, postoperative complications, and positive margins [106]. Like other minimally invasive approaches, robotic thymectomy has been associated with fewer postoperative complications and shorter length of stay when compared to transsternal.

One prospective study examined differences in patient quality of life after robotic and transsternal thymectomy. It found that those who underwent robotic thymectomy returned to baseline physical functioning sooner than their counterparts who underwent transsternal thymectomy, who had significantly decreased physical functioning (baseline 81.5 vs 66.3, $p=0.001$ ) and role functioning (baseline 71.9 vs $40.8, p=0.001$ ) scores a month after surgery. Additionally, those who underwent transsternal thymectomy had increased pain (baseline 15.2 vs 26.7, $p=0.017$ ) up to 3 months after surgery and significantly increased fatigue (baseline 34.3 vs $50.5, p=0.003$ ) 1 month after surgery whereas the robotic thymectomy group had returned to baseline at these timepoints [107]. A propensity matched retrospective cohort study comparing open vs robotic 
thymectomies found shorter hospital stays $(5.25 \pm 2.27$ days vs $12.31 \pm 13.62$ days, $p=0.003$ for robot and open respectively) and no differences in operative time or postoperative complications (208.19 $\pm 99.69 \mathrm{~min}$ vs $195.69 \pm 51.45 \mathrm{~min}$ robot and open respectively). Similar to the previous study, patients in the open group had higher postoperative pain scores as measured by a visual analog scale (VAS) compared to robot cases $(p<0.001)$ however, this was not supported by a significant reduction in analgesic medication use [74]. Additionally, when discussing myasthenia gravis, it is important to consider complete remission rates. Previous studies have demonstrated similar CSR rates between the two approaches with probabilities of CSR in robotic cases 28-42\% [71, $68,69,108]$ and rates for transsternal thymectomies from $17-34 \%[65,109]$.

\subsubsection{Robotic vs VATS Thymectomy}

There have been a few studies which have aimed to compare VATS and robotic thymectomies in terms of operative time, complication rates, and remission rates. Overall, robotic thymectomy appears to have similar perioperative outcomes and remission rates to VATS. With regards to operative time, there have been mixed results between studies. A single center retrospective study found significantly longer operative times with the robot (139.80 vs $121.07 \mathrm{~min}, p<0.05$ ) [110] while others found no difference $[68,73]$. A retrospective cohort study comparing VATS and robotic thymectomies found similar conversion rates of $1.4 \%$ in the robotic group compared to a rate of $1.3 \%$ in the thoracoscopic group. Additionally, there were no 30-day mortalities in either group and overall postoperative morbidity rates were low in both groups $(2.7 \%$ and $2.5 \%$ for robot and VATS, respectively) [68]. Another retrospective study found no significant differences in postoperative complications or morbidity between VATS and robotic cases but did note shorter hospital stays in the robot group ( $1.3 \pm 0.82$ vs $2.4 \pm 3.2$ days, $p=0.01$ for robot and VATS respectively) [73].

Considering the greater degrees of motion with the robotic arms, one could argue that thymectomies performed via this approach may be able to achieve improved resection and thus have increased rates of symptom reduction and remission. Overall, long term follow up data for robotic cases are lacking but similar symptom reduction and remission rates to VATS cases have been demonstrated. Solis-Pazmino et al performed a meta-analysis of 13 studies comparing the various approaches to thymectomy. When comparing VATS thymectomy to its robotic counterpart in terms of complete stable remission, robotic extended thymectomy appeared to have higher CSR rates at 3 years (RR 1.99, 95\% $\mathrm{Cl} 1.16-3.42, \mathrm{p}=0.01$ ). However, this advantage was not observed at 5 years ( $R R$ 1.10, 95\% $\mathrm{Cl} 0.76-1.6, p=0.62$ ). It is important to note that the quality of evidence in this analysis was low due partially to the small cohort sizes of the studies included. Thus, prospective randomized trials are required to draw definitive conclusions on remission rates between approaches [104]. Wei and D'Amico detail the literature on robotic vs VATS thymectomy [95]. With regards to symptom reduction, they note that studies have found reduction in symptoms similar to VATS resections in $87 \%$ of patients at 45 months [69], 82\% at 26 months [111], and $90 \%$ at $17-24$ months $[92,112]$.

\subsubsection{Arguments Against the Robot}

The robotic platform is not without its potential disadvantages. One of the larger arguments against the robot is its increased cost. When comparing costs of VATS vs robotic thymectomies, the robotic approach was found to be much more expensive in initial costs for the platform as well as 
fixed and material costs [97]. Conversely, another study compared the total costs of VATS and robotic thymectomies and found no significant differences $(\$ 14,743 \pm \$ 13,113$ vs $\$ 14,075 \pm \$ 4,439$, $p=0.71$ for VATS and robot respectively) [73]. Another argument against the robotic approach is the learning curve associated with the platform. Studies, however, have demonstrated a steep learning curve for robotic thymectomies. Power et al. [113] performed a systematic review on robotic thymectomies and lung resections and found that operative time was significantly reduced after 15-20 robotic thymectomies. There were mixed results regarding changes in length of stay and complications after the learning curve. However, this significant reduction in operating time after completing 15-20 cases was demonstrated in another single center retrospective study which utilized a propensity match. There were additionally no significant differences in blood loss, complications, conversion rate, and length of stay between early and late cases [114].

Another argument against the robot includes concerns regarding the lack of tactile feedback as opposed to VATS. However, as described in previous sections, studies comparing VATS and robotic thymectomies have demonstrated largely similar perioperative outcomes. Thus, this doesn't appear to significantly impact outcomes of patients when compared to other minimally invasive approaches.

\section{Discussion}

While thymectomy has been performed for more than 100 years, technique and approach have shifted with time to minimally invasive approaches. In the last century, usefulness of thymectomy for myasthenia gravis was debated due to spontaneous remission and lack of randomized trials. However, the MGTX trial [16] was the first major randomized trial that found surgery to be superior to medical therapy in patients with non-thymomatous myasthenia gravis. This study has led to the professional societal recommendation of thymectomy in appropriate surgical candidates with antiAchR positive disease [17]. In those with thymomas, thymectomy has been less debated and considered an appropriate surgical indication. To date, thymectomy use in certain patient subsets (elderly or pregnant patients) has been less studied and is not currently recommended as standard of care.

Myasthenia patients themselves must undergo careful workup and often require unique intraoperative management including consideration of anesthesia choice. They also must be monitored closely in the post-operative setting for development of myasthenic crises.

Current literature now supports the use of minimally invasive thymectomy as it has been associated with reduced complication rates and improved patient outcomes as well as shorter hospital length of stay. These advantages are particularly important now during the COVID pandemic. However, differences in outcomes do appear to vary when compared to either the transcervical vs transsternal approaches and there remains a need for prospective randomized trials comparing open vs minimally invasive approaches.

\section{Conclusion}

Based on our review, thymectomy for thymoma or anti-AchR positive non-thymomatous disease is indicated in appropriate surgical candidates with the latter now validated in a randomized clinical trial. Use of minimally invasive techniques appears to be safe and associated with improved post- 
operative outcomes overall and is routinely used now in our practice. However, prospective randomized trials are needed in the future to validate these findings.

\section{Acknowledgements}

We would like to acknowledge Jack Mitchell for his generous donation which helped make this work possible.

\section{Author Contributions}

ARD, ALD, MTJ all contributed to data accumulation, analysis, interpretation of results, and drafting of the manuscript.

\section{Funding}

This study was supported in part by the generous donation of the Jack Mitchell Thoracic Oncology Fund.

\section{Competing Interest}

The authors have declared that no competing interests exist.

\section{References}

1. Strauss AJ, Seegal BC, Hsu KC, Burkholder PM, Nastuk WL, Osserman KE. Immunofluorescence demonstration of a muscle binding, complement-fixing serum globulin fraction in myasthenia gravis. Exp Biol Med. 1960; 105: 184-191.

2. Patrick J, Lindstrom J. Autoimmune response to acetylcholine receptor. Science. 1973; 180 : 871-872.

3. ARORA Y, LEVIN K. Myasthenia gravis: Newer therapies offer sustained improvement. Cleve Clin J Med. 2013; 80: 711-721.

4. Cataneo AJ, Felisberto Jr G, Cataneo DC. Thymectomy in nonthymomatous myasthenia gravissystematic review and meta-analysis. Orphanet J Rare Dis. 2018; 13: 99.

5. Berrih-Aknin S, Frenkian-Cuvelier M, Eymard B. Diagnostic and clinical classification of autoimmune myasthenia gravis. J Autoimmun. 2014; 48: 143-148.

6. Zisimopoulou P, Evangelakou P, Tzartos J, Lazaridis K, Zouvelou V, Mantegazza R, et al. A comprehensive analysis of the epidemiology and clinical characteristics of anti-LRP4 in myasthenia gravis. J Autoimmun. 2014; 52: 139-145.

7. Oosterhuis HJGH, Kuks JBM. Myasthenia gravis with thymoma. In: Epithelial Tumors of the Thymus: Pathology, Biology, Treatment. New York: Springer; 1997. pp.271-280.

8. Srirajaskanthan R, Toubanakis C, Dusmet M, Caplin ME. A review of thymic tumours. Lung Cancer. 2008; 60: 4-13.

9. Thomas CR, Wright CD, Loehrer PJ. Thymoma: State of the art. J Clin Oncol. 1999; 17: 22802289.

10. Oosterhuis HJ. The natural course of myasthenia gravis: A long term follow up study. J Neurol Neurosurg Psychiatry. 1989; 52: 1121-1127. 
11. Potagas C, Dellatolas G, Tavernarakis A, Molari H, Mourtzouhou P, Koutra $H$, et al. Myasthenia gravis: Changes observed in a 30-years retrospective clinical study of a hospital-based population. J Neurol. 2004; 251: 116-117.

12. Mao ZF, Mo XA, Qin C, Lai YR, Hackett ML. Incidence of thymoma in myasthenia gravis: A systematic review. J Clin Neurol. 2012; 8: 161-169.

13. Blalock A, Mason MF, Morgan HJ, Riven S. Myasthenia gravis and tumors of the thymic region: Report of a case in which the tumor was removed. Ann Surg. 1939; 110: 544-561.

14. Sauerbruch $\mathrm{H}$, Schumacher $\mathrm{CB}$, Roth J. Thymektomie bei einem fall von morbus basedowi mit myasthenie. Mitteil Grenzgeb Med Chir. 1913; 25: 746-765.

15. Perlo VP, Poskanzer DC, Schwab RS, Viets HR, Osserman KE, Genkins G. Myasthenia gravis: Evaluation of treatment in 1,355 patients. Neurology. 1966; 16: 431-439.

16. Wolfe GI, Kaminski HJ, Aban IB, Minisman G, Kuo HC, Marx A, et al. Randomized trial of thymectomy in myasthenia gravis. N Engl J Med. 2016; 375: 511-522.

17. Gronseth GS, Barohn R, Narayanaswami P. Practice advisory: Thymectomy for myasthenia gravis (practice parameter update): Report of the guideline development, dissemination, and implementation subcommittee of the American academy of neurology. Neurology. 2020; 94: 705-709.

18. Kadota Y, Horio H, Mori T, Sawabata N, Goto T, Yamashita SI, et al. Perioperative management in myasthenia gravis: Republication of a systematic review and a proposal by the guideline committee of the Japanese Association for Chest Surgery 2014. Gen Thorac Cardiovasc Surg. 2015; 63: 201-215.

19. Aydin Y, Ulas AB, Mutlu V, Colak A, Eroglu A. Thymectomy in myasthenia gravis. Eurasian J Med. 2017; 49: 48-52.

20. Aoki S, Nagashima K, Furuta M, Makioka K, Fujita Y, Saito K, et al. A case of anti-Lrp4 antibodyassociated myasthenia gravis with a rare complication of thymoma successfully treated by thymectomy. Intern Med. 2020; 59: 1219-1222.

21. Koneczny I, Rennspiess D, Marcuse F, Dankerlui N, Hamid MA, Mané-Damas M, et al. Characterization of the thymus in Lrp4 myasthenia gravis: Four cases. Autoimmun Rev. 2019; 18: 50-55.

22. Cea G, Benatar M, Verdugo RJ, Salinas RA. Thymectomy for non-thymomatous myasthenia gravis. Cochrane Database Syst Rev. 2013. Doi: 10.1002/14651858.CD008111.pub2.

23. Soleimani A, Moayyeri A, Akhondzadeh S, Sadatsafavi M, Shalmani HT, Soltanzadeh A. Frequency of myasthenic crisis in relation to thymectomy in generalized myasthenia gravis: $A$ 17-year experience. BMC Neurol. 2004; 4: 12.

24. Buckingham JM, Howard Jr FM, Bernatz PE, Payne WS, Harrison Jr EG, O'Brien PC, et al. The value of thymectomy in myasthenia gravis: A computer-assisted matched study. Ann Surg. 1976; 184: 453-458.

25. Kawaguchi N, Kuwabara S, Nemoto Y, Fukutake T, Arimura K, Osame M, et al. Effects of thymectomy on late-onset myasthenia gravis without thymoma. Clin Neurol Neurosurg. 2007; 109: 858-861.

26. Bedlack RS, Sanders DB. Steroids have an important role. Muscle Nerve. 2002; 25: 117-121.

27. Jaretzki Al, Barohn RJ, Ernstoff RM, Kaminski HJ, Keesey JC, Penn AS, et al. Myasthenia gravis: Recommendations for clinical research standards. Neurology. 2000; 55: 16-23. 
28. Singh N, Goyal V. Thymectomy in non-thymomatous myasthenia gravis: Does an Rct solve the 75-year-old controversy? Ann Indian Acad Neurol. 2020; 23: 10-12.

29. Otsuka R, Ueda K, Tanaka T, Murakami J, Hayashi M, Hamano K. Who will benefit from thymectomy for myasthenia gravis? Is there any role for this procedure in elderly patients? Ann Transl Med. 2019; 7: 4.

30. Lorenzana P, Casallas A, Vega D, Aguirre C, Hedmont D, Posso $H$, et al. Timectomía vs tratamiento médico. 1999; 24: 8.

31. Sanders DB, Wolfe GI, Benatar M, Evoli A, Gilhus NE, Illa I, et al. International consensus guidance for management of myasthenia gravis: Executive summary. Neurology. 2016; 87: 419425.

32. Krucylak PE, Naunheim KS. Preoperative preparation and anesthetic management of patients with myasthenia gravis. Semin Thorac Cardiovasc Surg. 1999; 11: 47-53.

33. Blichfeldt-Lauridsen L, Hansen BD. Anesthesia and myasthenia gravis. Acta Anaesthesiol Scand. 2012; 56: 17-22.

34. Jamal BT, Herb K. Perioperative management of patients with myasthenia gravis: Prevention, recognition, and treatment. Oral Surg Oral Med Oral Pathol Oral Radiol Endod. 2009; 107: 612615.

35. Cata JP, Lasala JD, Williams W, Mena GE. Myasthenia gravis and thymoma surgery: A clinical update for the cardiothoracic anesthesiologist. J Cardiothorac Vasc Anesth. 2019; 33: 25372545.

36. Leventhal SR, Orkin FK, Hirsh RA. Prediction of the need for postoperative mechanical ventilation in myasthenia gravis. Anesthesiology. 1980; 53: 26-30.

37. Loach AB, Young AC, Spalding JM, Smith AC. Postoperative management after thymectomy. $B r$ Med J. 1975; 1: 309-312.

38. Lee HS, Lee HS, Lee HE, Bae MK, Chung KY, Shin HY, et al. Predictive factors for myasthenic crisis after videoscopic thymectomy in patients with myasthenia gravis. Muscle Nerve. 2015; 52: 216220.

39. Watanabe A, Watanabe T, Obama T, Mawatari T, Ohsawa H, Ichimiya $\mathrm{Y}$, et al. Prognostic factors for myasthenic crisis after transsternal thymectomy in patients with myasthenia gravis. J Thorac Cardiovasc Surg. 2004; 127: 868-876.

40. Leuzzi G, Meacci E, Cusumano G, Cesario A, Chiappetta M, Dall'Armi V, et al. Thymectomy in myasthenia gravis: Proposal for a predictive score of postoperative myasthenic crisis. Eur J Cardiothorac Surg. 2014; 45: e76-e88.

41. Xue L, Wang L, Dong J, Yuan Y, Fan H, Zhang Y, et al. Risk factors of myasthenic crisis after thymectomy for thymoma patients with myasthenia gravis. Eur J Cardiothorac Surg. 2017; 52: 692-697.

42. Liu C, Liu P, Qi G. Assessment of the risks of a myasthenic crisis after thymectomy in patients with myasthenia gravis: A systematic review and meta-analysis of 25 studies. J Cardiothorac Surg. 2020; 15: 270.

43. Kanai T, Uzawa A, Sato Y, Suzuki S, Kawaguchi N, Himuro K, et al. A clinical predictive score for postoperative myasthenic crisis. Ann Neurol. 2017; 82: 841-849.

44. Melzer N, Ruck T, Fuhr P, Gold R, Hohlfeld R, Marx A, et al. Clinical features, pathogenesis, and treatment of myasthenia gravis: A supplement to the Guidelines of the German Neurological Society. J Neurol. 2016; 263: 1473-1494. 
45. Alipour-Faz A, Shojaei M, Peyvandi H, Ramzi D, Oroei M, Ghadiri F, et al. A comparison between IVIG and plasma exchange as preparations before thymectomy in myasthenia gravis patients. Acta Neurol Belg. 2017; 117: 245-249.

46. Sheikh S, Alvi U, Soliven B, Rezania K. Drugs that induce or cause deterioration of myasthenia gravis: An update. J Clin Med. 2021; 10: 1537.

47. Van Den Bersselaar LR, Snoeck MM, Gubbels M, Riazi S, Kamsteeg EJ, Jungbluth $H$, et al. Anaesthesia and neuromuscular disorders: What a neurologist needs to know. Pract Neurol. 2021; 21: 12-24.

48. Nitahara K, Sugi Y, Higa K, Shono S, Hamada T. Neuromuscular effects of sevoflurane in myasthenia gravis patients. Br J Anaesth. 2007; 98: 337-341.

49. Maddali MM, Matreja PV, Zachariah M. Bispectral index-monitored anesthesia technique for transsternal thymectomy. Asian Cardiovasc Thorac Ann. 2009; 17: 389-394.

50. Chevalley C, Spiliopoulos A, de Perrot M, Tschopp JM, Licker M. Perioperative medical management and outcome following thymectomy for myasthenia gravis. Can J Anaesth. 2001; 48: 446-451.

51. Collins $\mathrm{S}$, Roberts $\mathrm{H}$, Hewer I. Anesthesia and perioperative considerations for patients with myasthenia gravis. AANA J. 2020; 88: 485-491.

52. Mouri H, Jo T, Matsui H, Fushimi K, Yasunaga H. Effect of Sugammadex on postoperative Myasthenic crisis in myasthenia gravis patients: Propensity score analysis of a Japanese nationwide database. Anesth Analg. 2020; 130: 367-373.

53. Gronseth GS, Barohn RJ. Practice parameter: Thymectomy for autoimmune myasthenia gravis (an evidence-based review): Report of the quality standards subcommittee of the American academy of neurology. Neurology. 2000; 55: 7-15.

54. Pulle MV, Asaf BB, Puri HV, Bishnoi S, Kumar A. Meta-analysis of limited thymectomy versus total thymectomy for Masaoka stage I and II thymoma. J Chest Surg. 2021; 54: 127-136.

55. Meyer DM, Herbert MA, Sobhani NC, Tavakolian P, Duncan A, Bruns M, et al. Comparative clinical outcomes of thymectomy for myasthenia gravis performed by extended transsternal and minimally invasive approaches. Ann Thorac Surg. 2009; 87: 385-391.

56. Holleran TJ, Napolitano MA, Crowder HR, Sparks AD, Antevil JL, Trachiotis GD. Clinical outcomes and technical approach of thymectomy in the veterans health administration. Ann Thorac Surg. 2021. Doi: 10.1016/j.athoracsur.2021.05.020.

57. Di Crescenzo VG, Napolitano F, Panico C, Di Crescenzo RM, Zeppa P, Vatrella A, et al. Surgical approach in thymectomy: Our experience and review of the literature. Int J Surg Case Rep. 2017; 39: 19-24.

58. Kaiser L, Kron IL, Spray TL. Mastery of cardiothoracic surgery. The Alphen am Rhine: Wolters Kluwer; 2013.

59. Masaoka A, Yamakawa Y, Niwa H, Fukai I, Kondo S, Kobayashi M, et al. Extended thymectomy for myasthenia gravis patients: A 20-year review. Ann Thorac Surg. 1996; 62: 853-859.

60. Mack MJ, Landreneau RJ, Yim AP, Hazelrigg SR, Scruggsa GR. Results of video-assisted thymectomy in patients with myasthenia gravis. J Thorac Cardiovasc Surg. 1996; 112: 13521360.

61. Calhoun RF, Ritter JH, Guthrie TJ, Pestronk A, Meyers BF, Patterson GA, et al. Results of transcervical thymectomy for myasthenia gravis in 100 consecutive patients. Ann Surg. 1999; 230: 555. 
62. Mineo TC, Pompeo E, Lerut TE, Bernardi G, Coosemans W, Nofroni I. Thoracoscopic thymectomy in autoimmune myasthenia: Results of left-sided approach. Ann Thorac Surg. 2000; 69: 1537-1541.

63. De Perrot M, Bril V, McRae K, Keshavjee S. Impact of minimally invasive trans-cervical thymectomy on outcome in patients with myasthenia gravis. Eur J Cardiothorac Surg. 2003; 24: 677-683.

64. Chang PC, Chou SH, Kao EL, Cheng YJ, Chuang HY, Liu CK, et al. Bilateral video-assisted thoracoscopic thymectomy vs. extended transsternal thymectomy in myasthenia gravis: $A$ prospective study. Eur Surg Res. 2005; 37: 199-203.

65. Kattach H, Anastasiadis K, Cleuziou J, Buckley C, Shine B, Pillai R, et al. Transsternal thymectomy for myasthenia gravis: Surgical outcome. Ann Thorac Surg. 2006; 81: 305-308.

66. Shrager JB, Nathan D, Brinster CJ, Yousuf O, Spence A, Chen Z, et al. Outcomes after 151 extended transcervical thymectomies for myasthenia gravis. Ann Thorac Surg. 2006; 82: 18631869.

67. Lin MW, Chang YL, Huang PM, Lee YC. Thymectomy for non-thymomatous myasthenia gravis: A comparison of surgical methods and analysis of prognostic factors. Eur J Cardiothorac Surg. 2010; 37: 7-12.

68. Rückert JC, Swierzy M, Ismail M. Comparison of robotic and nonrobotic thoracoscopic thymectomy: A cohort study. J Thorac Cardiovasc Surg. 2011; 141: 673-677.

69. Freeman RK, Ascioti AJ, Van Woerkom JM, Vyverberg A, Robison RJ. Long-term follow-up after robotic thymectomy for nonthymomatous myasthenia gravis. Ann Thorac Surg. 2011; 92: 10181023.

70. Tomulescu V, Sgarbura O, Stanescu C, Valciu C, Campeanu A, Herlea V, et al. Ten-year results of thoracoscopic unilateral extended thymectomy performed in nonthymomatous myasthenia gravis. Ann Surg. 2011; 254: 761-766.

71. Marulli G, Schiavon M, Perissinotto E, Bugana A, Di Chiara F, Rebusso A, et al. Surgical and neurologic outcomes after robotic thymectomy in 100 consecutive patients with myasthenia gravis. J Thorac Cardiovasc Surg. 2013; 145: 730-736.

72. Xie X, Gan X, Chen B, Shen Z, Wang M, Zhang $H$, et al. Left-and right-sided video-assisted thoracoscopic thymectomy exhibit similar effects on myasthenia gravis. J Thorac Dis. 2016; 8: 124-132.

73. Imielski B, Kurihara C, Manerikar A, Chaudhary S, Kosterski S, Odell D, et al. Comparative effectiveness and cost-efficiency of surgical approaches for thymectomy. Surgery. 2020; 168: 737-742.

74. Luzzi L, Corzani R, Ghisalberti M, Meniconi F, De Leonibus L, Molinaro F, et al. Robotic surgery vs. open surgery for thymectomy, a retrospective case-match study. J Robot Surg. 2021; 15: 375-379.

75. Sonett JR, Jaretzki A. Thymectomy for nonthymomatous myasthenia gravis: A critical analysis. Ann N Y Acad Sci. 2008; 1132: 315-328.

76. Blalock A. Thymectomy in the treatment of myasthenia gravis: Report of twenty cases. J Thorac Cardiovasc Surg. 1944; 13: 316-339.

77. Blalock A, Harvey AM, Ford FR, LILIENTHAL JL. The treatment of myasthenia gravis by removal of the thymus gland: Preliminary report. JAMA. 1941; 117: 1529-1533. 
78. Kirschner PA, Osserman KE, Kark AE. Studies in myasthenia gravis: Transcervical total thymectomy. JAMA. 1969; 209: 906-910.

79. Papatestas AE, Genkins GA, Kornfeld PE, Eisenkraft JB, Fagerstrom RP, Pozner JA, et al. Effects of thymectomy in myasthenia gravis. Ann Surg. 1987; 206: 79-88.

80. Masaoka A, Nagaoka Y, Kotake Y. Distribution of thymic tissue at the anterior mediastinum: Current procedures in thymectomy. J Thorac Cardiovasc Surg. 1975; 70: 747-754.

81. Jaretzki III A, Bethea M, Wolff M, Olarte MR, Lovelace RE, Penn AS, et al. A rational approach to total thymectomy in the treatment of myasthenia gravis. Ann Thorac Surg. 1977; 24: 120-130.

82. Jaretzki III A, Wolff M. "Maximal" thymectomy for myasthenia gravis: Surgical anatomy and operative technique. J Thorac Cardiovasc Surg. 1988; 96: 711-716.

83. Cooper JD, Al-Jilaihawa AN, Pearson FG, Humphrey JG, Humphrey HE. An improved technique to facilitate transcervical thymectomy for myasthenia gravis. Ann Thorac Surg. 1988; 45: 242247.

84. Shrager JB. Extended transcervical thymectomy: The ultimate minimally invasive approach. Ann Thorac Surg. 2010; 89: S2128-S2134.

85. Shrager JB, Deeb ME, Mick R, Brinster CJ, Childers HE, Marshall MB, et al. Transcervical thymectomy for myasthenia gravis achieves results comparable to thymectomy by sternotomy. Ann Thorac Surg. 2002; 74: 320-327.

86. Deeb ME, Brinster CJ, Kucharzuk J, Shrager JB, Kaiser LR. Expanded indications for transcervical thymectomy in the management of anterior mediastinal masses. Ann Thorac Surg. 2001; 72: 208-211.

87. Roviaro G, Rebuffat C, Varoli F, Vergani C, Maciocco M, Scalambra SM. Videothoracoscopic excision of mediastinal masses: Indications and technique. Ann Thorac Surg. 1994; 58: 16791683.

88. Sugarbaker DJ. Thoracoscopy in the management of anterior mediastinal masses. Ann Thorac Surg. 1993; 56: 653-656.

89. Sabbagh MN, Garza JS, Patten B. Thoracoscopic thymectomy in patients with myasthenia gravis. Muscle Nerve. 1995; 18: 1475-1477.

90. Yoshino I, Hashizume $M$, Shimada $M$, Tomikawa $M$, Tomiyasu $M$, Suemitsu $R$, et al. Thoracoscopic thymomectomy with the da Vinci computer-enhanced surgical system. J Thorac Cardiovasc Surg. 2001; 122: 783-785.

91. Ashton Jr RC, McGinnis KM, Connery CP, Swistel DG, Ewing DR, DeRose Jr JJ. Totally endoscopic robotic thymectomy for myasthenia gravis. Ann Thorac Surg. 2003; 75: 569-571.

92. Rea F, Bortolotti L, Girardi R, Sartori F. Thoracoscopic thymectomy with the 'da Vinci'surgical system in patient with myasthenia gravis. Interact Cardiovasc Thorac Surg. 2003; 2: 70-72.

93. Yim AP, Kay RL, Ho JK. Video-assisted thoracoscopic thymectomy for myasthenia gravis. Chest. 1995; 108: 1440-1443.

94. Liu Z, Yang J, Lin L, Huang J, Jiang G. Unilateral video-assisted thoracoscopic extended thymectomy offers long-term outcomes equivalent to that of the bilateral approach in the treatment of non-thymomatous myasthenia gravis. Interact Cardiovasc Thorac Surg. 2015; 21: 610-615.

95. Wei B, D’Amico TA. Thoracoscopic versus robotic approaches: Advantages and disadvantages. Thorac Surg Clin. 2014; 24: 177-188. 
96. Pennathur A, Qureshi I, Schuchert MJ, Dhupar R, Ferson PF, Gooding WE, et al. Comparison of surgical techniques for early-stage thymoma: Feasibility of minimally invasive thymectomy and comparison with open resection. J Thorac Cardiovasc Surg. 2011; 141: 694-701.

97. Augustin F, Schmid T, Sieb M, Lucciarini P, Bodner J. Video-assisted thoracoscopic surgery versus robotic-assisted thoracoscopic surgery thymectomy. Ann Thorac Surg. 2008; 85: S768S771.

98. Lin TS, Tzao C, Lee SC, Wu CY, Shy CJ, Lee CY, et al. Comparison between video-assisted thoracoscopic thymectomy and transternal thymectomy for myasthenia gravis (analysis of 82 cases). Int Surg. 2005; 90: 36-41.

99. Manoly I, Whistance RN, Sreekumar R, Khawaja S, Horton JM, Khan AZ, et al. Early and midterm outcomes of trans-sternal and video-assisted thoracoscopic surgery for thymoma. Eur J Cardiothorac Surg. 2014; 45: e187-e193.

100.Shiono H, Kadota Y, Hayashi A, Okumura M. Comparison of outcomes after extended thymectomy for myasthenia gravis: Bilateral thoracoscopic approach versus sternotomy. Surg Laparosc Endosc Percutan Tech. 2009; 19: 424-427.

101. Hiratsuka M, Iwasaki A, Shirakusa T, Yoneda S, Yamamoto S, Shiraishi T, et al. Role of videoassisted thoracic surgery for the treatment of myasthenia gravis: Extended thymectomy by median sternotomy versus the thoracoscopic approach with sternal lifting. Int Surg. 2006; 91: 44-51.

102.Rückert JC, Sobel HK, Göhring S, Einhäupl KM, Müller JM. Matched-pair comparison of three different approaches for thymectomy in myasthenia gravis. Surg Endosc Other Interv Tech. 2003; 17: 711-715.

103.Rückert JC, Walter M, Müller JM. Pulmonary function after thoracoscopic thymectomy versus median sternotomy for myasthenia gravis. Ann Thorac Surg. 2000; 70: 1656-1661.

104.Solis-Pazmino P, Baiu I, Lincango-Naranjo E, Trope W, Prokop L, Ponce OJ, et al. Impact of the surgical approach to thymectomy upon complete stable remission rates in myasthenia gravis: A meta-analysis. Neurology. 2021. Doi:10.1212/WNL.0000000000012153.

105.Ismail M, Swierzy M, Rückert JC. State of the art of robotic thymectomy. World J Emerg Surg. 2013; 37: 2740-2746.

106.O'Sullivan KE, Kreaden US, Hebert AE, Eaton D, Redmond KC. A systematic review of robotic versus open and video assisted thoracoscopic surgery (VATS) approaches for thymectomy. Ann Cardiothorac Surg. 2019; 8: 174-193.

107. Balduyck B, Hendriks JM, Lauwers P, Mercelis R, Ten Broecke P, Van Schil P. Quality of life after anterior mediastinal mass resection: A prospective study comparing open with robotic-assisted thoracoscopic resection. Eur J Cardiothorac Surg. 2011; 39: 543-548.

108.Keijzers $M$, de Baets $M$, Hochstenbag M, Abdul-Hamid M, Zur Hausen A, van der Linden M, et al. Robotic thymectomy in patients with myasthenia gravis: Neurological and surgical outcomes. Eur J Cardiothorac Surg. 2015; 48: 40-55.

109.Spillane J, Hayward M, Hirsch NP, Taylor C, Kullmann DM, Howard RS. Thymectomy: Role in the treatment of myasthenia gravis. J Neurol. 2013; 260: 1798-1801.

110.Jun Y, Hao L, Demin L, Guohua D, Hua J, Yi S. Da Vinci robot-assisted system for thymectomy: Experience of 55 patients in China. Int J Med Robot. 2014; 10: 294-299.

111.Goldstein SD, Yang SC. Assessment of robotic thymectomy using the Myasthenia Gravis Foundation of America Guidelines. Ann Thorac Surg. 2010; 89: 1080-1086. 
112.Bodner J, Wykypiel H, Wetscher G, Schmid T. First experiences with the da Vinci ${ }^{\mathrm{TM}}$ operating robot in thoracic surgery. Eur J Cardiothorac Surg. 2004; 25: 844-851.

113.Power AD, D'Souza DM, Moffatt-Bruce SD, Merritt RE, Kneuertz PJ. Defining the learning curve of robotic thoracic surgery: What does it take? Surg Endosc. 2019; 33: 3880-3888.

114.Kamel MK, Rahouma M, Stiles BM, Nasar A, Altorki NK, Port JL. Robotic thymectomy: Learning curve and associated perioperative outcomes. J Laparoendosc Adv Surg Tech. 2017; 27: 685690.

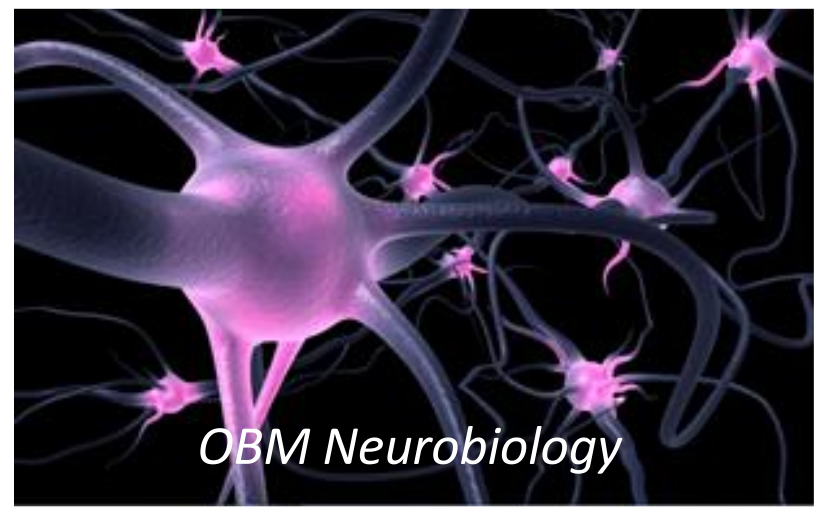

Enjoy OBM Neurobiology by:

1. Submitting a manuscript

2. Joining volunteer reviewer bank

3. Joining Editorial Board

4. Guest editing a special issue

For more details, please visit:

http://www.lidsen.com/journals/neurobiology 